\title{
Control Strategy and Performance Simulation Study on Extended Range Electric Vehicle
}

\author{
Limian Wang ${ }^{1,2}$, Shumao Wang ${ }^{1, *}$, and Zhenghe Song ${ }^{1}$ \\ ${ }^{1}$ College of Engineering, China Agricultural University, Beijing 100083, China \\ 2 Beijing Automotive Technician College, Beijing 102606, China
}

\begin{abstract}
Electric vehicles are recognized as an effective way to alleviate the energy crisis and environmental degradation, and extended range electric vehicles which have both the technical advantages of hybrid electric vehicles and pure electric vehicles, have gradually become a research hotspot in the automotive industry. In this paper, the system structure design of the extended range electric vehicle is carried out. On the basis of the pure electric vehicle, the engine and generator set are added. The control strategy model is established and the simulation research is carried out. The results show that the proposed control strategy model optimizes the working range of the range extender, takes into account the performance of the battery and the drive motor, and shows good tracking characteristics.
\end{abstract}

\section{Preface}

There are some factors which limit the marketization and industrialization development of electric vehicles(EV) at the present phase, such as the EV's battery power capacity, lifetime and cost. But EV is recognized as an effective way to relieve the energy crisis and environmental deterioration, so the extended range electric vehicle(E-REV) is seen as a good way to extend the driving range, and it has technology advantages of both hybrid electric vehicles and pure electric vehicles. A lot of companies, research institutions, colleges and universities have carried out many years of research and practice on E-REV, and mainly focus on the research field of the design and the control effect of the extended range engine $e^{[1-3]}$. Studies on the process control strategy of vehicle equipped with the range extender(RE) are different because of different vehicle performance targets.

In this paper, the system structure design of E-REV is carried out. On the basis of the pure electric vehicle, the engine and generator set are added. The control strategy model is established and the simulation research is carried out.

\section{E-REV structure and control strategies}

An engine and a generator are added to EV as shown in figure 1 below, so the E-REV has the EV's characteristics ${ }^{[1-3]}$.Compared with the traditional hybrid electric vehicle, the engine power of the E-REV is small, and the motor and battery power of the E-REV are relatively large.

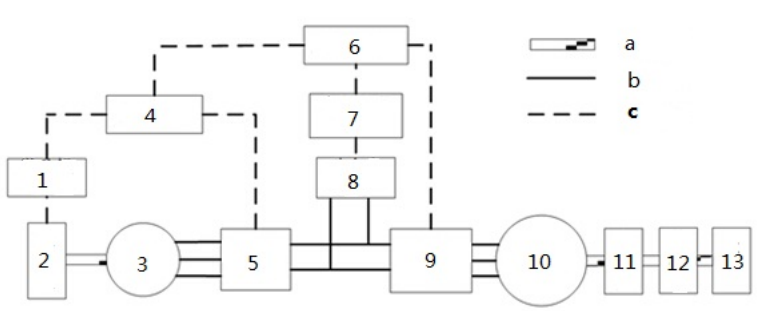

Fig. 1. System structure of E-REV

Numbers and letters represent the following meanings.

1. Engine control unit.

2. Engine.

3. Generator.

4. Range extender control unit.

5. Generator control unit.

6. Vehicle control unit.

7. Battery management system.

8. Battery.

9. Drive motor control unit.

10. Drive motor.

11. Transmission box.

12. Transmission shaft.

13. Vehicle wheel.

a. Mechanical transmission.

b. Electrical power supply.

c. Control signal connection.

The vehicle powertrain parameter is shown in table 1 below. Drive motor is the main power source. The range extender control unit is composed of engine and generator, the main function of which is to increase the driving range of electric vehicles. The control of range extender is related to mutual coupling of many variables, which is the key to optimize the performance of electric

\footnotetext{
* Corresponding author: wangshumao@cau.edu.cn
} 
vehicle. Currently, there are two control strategies, thermostat and power following. The thermostat needs high performance battery, and it will affect the battery lifetime. The power following can improve the battery running state, but needs high performance engine, and the running range is wide, so the fuel consumption is $\operatorname{high}^{[2-4]}$.

Table 1. Basic parameter of the powertrain

\begin{tabular}{|c|c|c|}
\hline System & Parameter type and unit & Value \\
\hline \multirow{3}{*}{ Engine } & Peak power $/ \mathrm{kw}$ & $84 / 6000$ \\
\cline { 2 - 3 } & Peak torque $/ \mathrm{Nm}$ & $142 / 4800$ \\
\hline \multirow{3}{*}{ Generator } & Rated power $/ \mathrm{kw}$ & 35 \\
\cline { 2 - 3 } & Peak torque $/ \mathrm{Nm}$ & 180 \\
\cline { 2 - 3 } & Max speed $/ \mathrm{rpm}$ & 6000 \\
\hline \multirow{2}{*}{$\begin{array}{c}\text { Drive } \\
\text { motor }\end{array}$} & Rated power $/ \mathrm{kw}$ & 50 \\
\cline { 2 - 3 } & Peak power $/ \mathrm{kw}$ & 100 \\
\hline \multirow{3}{*}{ Battery } & Max speed $/ \mathrm{rpm}$ & 6000 \\
\cline { 2 - 3 } & Capacity at $20^{\circ} \mathrm{C} / \mathrm{kwh}$ & 9.07 \\
\cline { 2 - 3 } & Continuous discharge power & 350.4 \\
\hline
\end{tabular}

\section{Establishment of control strategy model}

In the power following control strategy, the drive motor power will change fast following the vehicle state, and it's hard to use mathematic model to descript the changing ${ }^{[5-7]}$. In this paper, we use the time series prediction and build the sequential index smoothing model to predict the drive motor power based on historical data of motor power. The principle is that, using the weighted average value to predict future observation value and giving more weighted coefficient to the observation value which are more close to the prediction value, and the weighted value is distributed by the exponential law, while the weighted factor changes exponentially based on sequential prediction data, and the sequential index is an actual geometrical progression [8-10].

$\mathrm{P}_{\mathrm{t} 1}$ is set as the actual drive motor power and $\mathrm{S}_{\mathrm{t} 1}$ as the smooth predictive value at $\mathrm{t}_{1}$ moment, so the motor power is predicted by the sequential index smoothing model as follows.

$$
\mathrm{S}_{\mathrm{t} 1+1}=\alpha \mathrm{P}_{\mathrm{t} 1}+(1-\alpha) \mathrm{S}_{\mathrm{t} 1}
$$

$\alpha$ is a model factor in the formula, and its value is between $0 \sim 1$. In the significant change sequential, prediction value has small dependency to the nearby sequential data, so we can use the small $\alpha$, otherwise, we use the big $\alpha$. The first smoothing data is the first actual data in the model as follows.

$$
\mathrm{S}_{1}=\mathrm{P}_{1}
$$

$$
\begin{aligned}
& \mathrm{S}_{\mathrm{t} 1+1}=\alpha \mathrm{P}_{\mathrm{t} 1}+\alpha(1-\alpha) \mathrm{P}_{\mathrm{t} 1-1}+\alpha(1-\alpha)^{2} \mathrm{P}_{\mathrm{t} 1-2} \\
& +\alpha(1-\alpha)^{3} \mathrm{P}_{\mathrm{t} 1-3}+\alpha(1-\alpha)^{4} \mathrm{P}_{\mathrm{t} 1-4}+\ldots
\end{aligned}
$$

In the vehicle controlling process, the prediction motor power will be input to the range extender as the steady state power demand, and APU optimizes the operating points according to the feedback power and current engine working state. The transient state power demand is met by the battery. In this model, $\alpha$ is 0.5 , so $\alpha(1-\alpha)^{4}$ is 0.03125 . The following component is much smaller, so it can be ignored. The sequential index is 5 .

\section{Simulation result analysis}

E-REV performance is simulated based on the NEDC cycle in the paper. Figure 2 shows the motor prediction model value and no prediction model value, and it also shows that, the original motor power changes fast, and the power following will make the range extender operating points change fast. After using the motor sequential index smoothing model, the motor demand power changes more smoothly. In small demand power changing conditions, the prediction value follows fast than the original demand power and prediction value follows more slowly with bigger demand power. This strategy can make the acceleration faster in the slow vehicle speed conditions. In high vehicle speed conditions, the lost battery power will fill up by the ranger extender to keep the acceleration performance. At the same time, the predictive power shows hysteresis under the condition of a large drop in the motor demand power, but it's good for stable operation and smooth unloading of range extender engine.

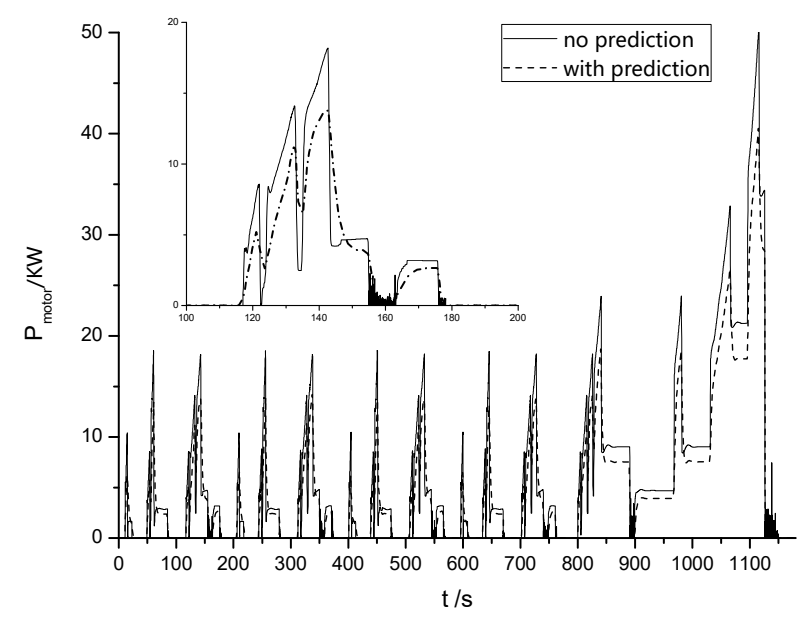

Figure 2. Influence of the model on motor demand power

The process of output power and battery SOC value trends are shown in figure 3. Seen from the figure, in NEDC cycle, battery SOC is set at $30 \%$ initially and changes to $28 \%$ at end of the cycle. From the whole process of view, SOC decreases slowly and the battery energy is mainly used for lower power demand in pure 
electric operating mode in the initial phase. When range extender engine operates, the batteries do not need continuous discharge. Coupled with energy recovery and timely charging of RE, it causes little change of SOC value. In the late NEDC cycle, with the vehicle driving power demand increasing, RE mainly used to meet the output power to drive the vehicle. At the same time according to the power demand prediction, the VCU coordinates energy distribution and tries to make RE work in the economic region with battery power supplement, which drives the vehicle together. So SOC decreases rapidly in the high vehicle speed region at the later stage of the cycle.

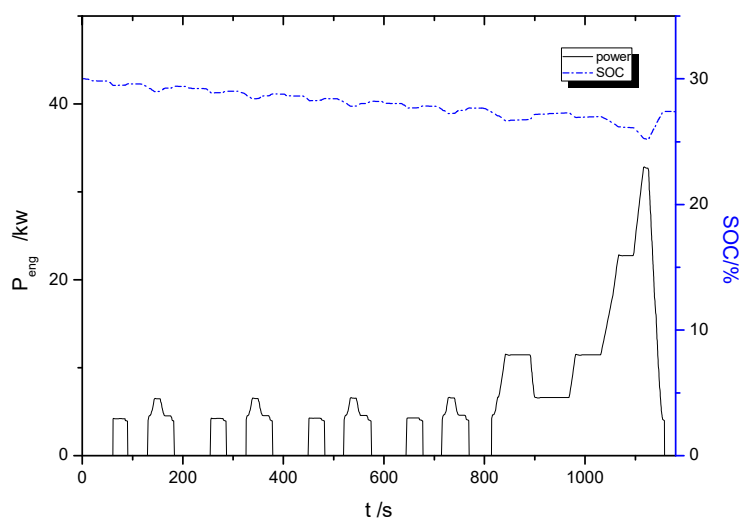

Figure 3. Power change of RE and SOC change

The change curve of the output power of the battery is shown in figure 4. Visibly, the battery power frequently changes. But in addition to the late segment of high power demand, the battery maximum output power is relatively stable, and it is always within the limits of continuous output power that the battery allows to output.

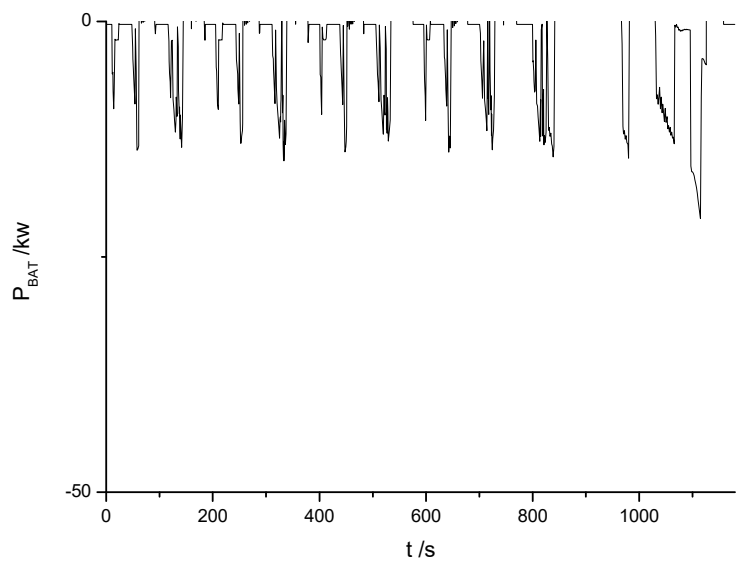

Figure 4. Change of output power of the battery

Also seen from figure 4, the batteries are mainly in response to transient changes in power demand under the coordination of vehicle control unit after the introduction of the model, which has played an electrically driven responsive advantage, at the same time it meets the limits of the battery output performance, and it also protects the battery to some extent.

The RE engine operating points during the NEDC cycle are shown in figure 5 . Seen from the figure, the engine operating points are approximately centred around a curve which covers a wide area of the engine speed, so there must be some points fall outside the economical region. But overall, RE operating region is different with the traditional surface area conditions. In the role of prediction models and control strategies, the work area is concentrated at the smoothing curve from $1800 \mathrm{rpm}$ to $3800 \mathrm{rpm}$. The condition of alternating mutation with external input disturbance that has been effectively controlled, which is conducive to approach the optimization point of the fuel consumption under these conditions.

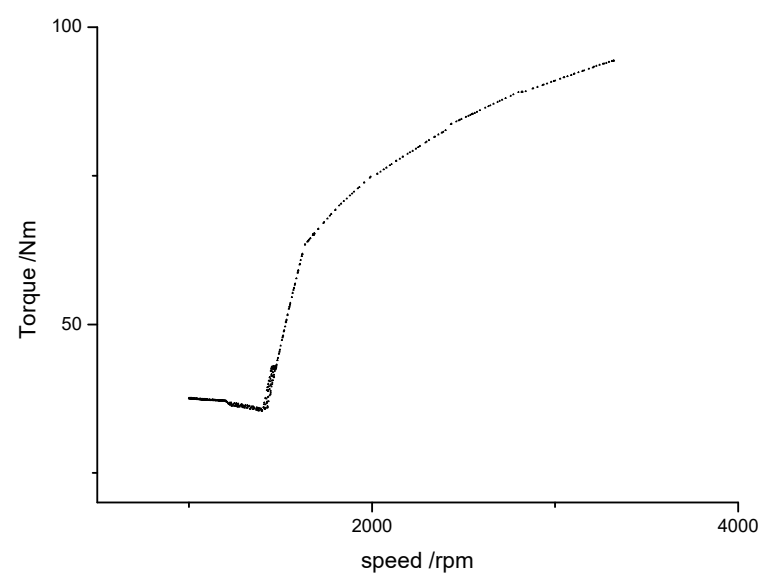

Figure 5. Operating conditions of RE

\section{Conclusions}

A control strategy model is established based on mathematical method. In small demand power changing conditions, the prediction value follows fast, while the prediction value follows more slowly with bigger demand power. The predictive power shows hysteresis under the condition of a large drop in the motor demand power.

According to control strategy model, the VCU coordinates energy distribution and tries to make RE work in the economic region with battery power supplement, and the work area is concentrated at the smoothing curve from $1800 \mathrm{rpm}$ to $3800 \mathrm{rpm}$, which is conducive to approach the optimization point of the fuel consumption.

After the control strategy brought in E-REV control system, the batteries are mainly in response to transient changes in power demand under the coordination of vehicle control unit. Especially in the lower vehicle power demand conditions, it has played an electrically driven responsive advantage. In big power demand conditions, although the battery discharge power increases, but it still can be maintained within the range of the battery permitted. 


\section{References}

1. Haitao Mi, Dongjin Ye \& Yuanbin Yu, Optimization of the Control Strategy for Range Extended Electric Vehicle, Automotive Engineering,2014,36(8):899-903

2. Jean J Bott, M James Grieve, John A MacBain. Electric Vehicle Range Extension Using an SOFC APU[C].SAE Paper 2005 -011172

3. Lijie Wang, Xiaozhong Liao, Yang Gao, \& Shuang Gao,Summarization of modeling and prediction of wind power generation, Power System Protection and Control, 2009, 37(13):118-121

4. Xiaodong Qu, Qingnian Wang \& Yuanbin Yu, A Study on the Control Strategy for APU in a Extended-range EV, Automotive Engineering, 2013, 35(9):763-768

5. Mehrdad Ehsani, Yimin Gao, Ali Emadi. Modern Electric, Hybrid Electric, and Fuel Cell Vehicles Fundamentals, Theory and Design[M]. Florida: CRC Press, 2010

6. A. Sciarrrtta, L. Serrao, P.C. Dewangan, et al. A Control Benchmark on the Energy Management of a Plug-in Hybrid Electric Vehicle[J]. Control Engineering Practice, 2014, 29:287-298

7. Aharon I,Kuperman A.Topological overview of power-trains for battery-powered vehicles with range extenders[J].IEEE Transactions on Power Electronics,2014,26(3)

8. Scott Varnhagen, Adam Same, Jesse Remillard, Jae Wan Park. A numerical investigation on the efficiency of range extending systems using Advanced Vehicle Simulator[J]. Journal of Power Sources, 2011, 196(6): 3360-3370

9. Tate E D,Harpster M O,Savagian P J.The electrification of the automobile:from conventional hybrid,to plug-in hybrids, to extended-range electric vehicles[J].SAE International Journal of Passenger Cars-Electronic and Electrical Systems,2015,1(1)

10. Lu L,Han X,Li J.A review on the key issues forlithium-ion battery management in electric vehicles[J].Journal of Power Sources,2013,226(C) 